\title{
EFFECT OF $\kappa$-CARRAGEENAN ON MECHANICAL, THERMAL AND BIODEGRADABLE PROPERTIES OF STARCH-CARBOXYMETHYL CELLULOSE (CMC) BIOPLASTIC
}

\author{
AKBAR HANIF DAWAM ABDULLAH, ${ }^{*}$ BONITA FIRDIANA, ${ }^{*}$ ROSSY CHOERUN NISSA, \\ RAHMAT SATOTO, ${ }^{*}$ MYRTHA KARINA, DINA FRANSISKA, ${ }^{* *}$ NURHAYATI, ${ }^{* *}$ AGUSMAN, ${ }^{* *}$ \\ HARI EKO IRIANTO, ${ }^{* *}$ PANJI PRIAMBUDI, ${ }^{* *}$ SRI MARLIAH ${ }^{*}$ and ISMADI ${ }^{* * *}$ \\ *Research Unit for Clean Technology, Indonesian Institute of Sciences, Republic of Indonesia \\ ${ }^{* *}$ Research Center for Marine and Fisheries Products, Processing and Biotechnology, \\ Ministry of Marine Affairs and Fisheries, Republic of Indonesia \\ ${ }^{* * *}$ Biomaterials Research Center, Cibinong Science Center, Indonesian Institute of Sciences, \\ Republic of Indonesia \\ $\bowtie$ Corresponding author: A. H. Dawam Abdullah,akba001@lipi.go.id
}

Received May 9, 2021

\begin{abstract}
Starch-carboxymethyl cellulose (CMC) bioplastics have limited mechanical properties. Carrageenan from seaweed is a potential reinforcement material for improving the mechanical properties of bioplastics. This study aimed to determine the effect of Kappa $(\kappa)$-carrageenan on the mechanical and thermal properties and biodegradability of starch-CMC bioplastics. In this study, carrageenan at concentrations of $0 \%, 10 \%, 15 \%, 20 \%, 25 \%$ and $30 \%$ was used. The meltmixing process was conducted at $130{ }^{\circ} \mathrm{C}$ for $4 \mathrm{~min}$, using a mixer and then hot-pressing $\left(30 \mathrm{kgf} / \mathrm{cm}^{2}\right)$ at $150{ }^{\circ} \mathrm{C}$ for 5 min. The results indicated that the higher $\kappa$-carrageenan concentration increased the strength of bioplastics up to 15.7 $\mathrm{MPa}$. The fracture analysis via scanning electron microscopy-energy-dispersive X-ray spectroscopy indicated the distribution of sulfur $(\mathrm{S})$ elements that described the dispersion of $\kappa$-carrageenan. The Fourier transform infrared spectroscopy spectra revealed that the interaction between the starch-CMC matrix and $\kappa$-carrageenan formed a tight hydrogen bond network. The lowest mass reduction observed by thermogravimetric analysis occurred in bioplastics with $25 \%$ carrageenan, decreasing by $48 \%$ compared with bioplastics without $\kappa$-carrageenan. The addition of $\kappa$ carrageenan was identified as not affecting the biodegradability of the bioplastics.
\end{abstract}

Keywords: $\kappa$-carrageenan, starch-CMC bioplastic, mechanical, thermal, biodegradability

\section{INTRODUCTION}

Starch-carboxymethyl cellulose (CMC) bioplastic is made from starch and is easily biodegraded. Starch as a raw material for bioplastics is widely used; however, its application has some limitations, such as its mechanical properties. The combination of starch and plasticizers (glycerol) makes the starch-CMC bioplastic more stretchable, but the tensile strength and elastic modulus are unsatisfying. These unfavorable properties have limited the structural applications of starch-CMC bioplastic. ${ }^{1}$ An enhancement of the mechanical properties of starch-CMC bioplastic is possible by mixing it with other biodegradable polymers. ${ }^{1}$ Therefore, it is important to investigate possible additives to improve the performance and mechanical properties of starch-CMC bioplastics.

Seaweed is a widely cultivated product. Indonesia is among many countries supplying seaweed to the international market. Carrageenan is one of the extracts that can be obtained from red seaweed (Rhodophyceae), which is a viscosifying polysaccharide and can form a gel. Moreover, it is a sulfated polygalactan containing $15 \%-40 \%$ sulfate ester. Carrageenan is also formed by the alternative units d-galactose and 3,6-anhydro-D-galactose, combined with the $\alpha$ 1,3 and $\beta-1,4$-glycosidic linkage. ${ }^{2,3}$ Carrageenan can be of several types, such as kappa ( $\kappa)$, iota (1), and lambda $(\lambda)$. 
Kappa ( $(\kappa)$-carrageenan exhibits excellent properties for forming gels and membranes that have better mechanical properties than other types. ${ }^{4}$

Carrageenan is generally used by the food, cosmetics and pharmaceutical industries. In the food industry, it is used in low concentrations as a gelling agent to stabilize suspensions and emulsions. ${ }^{5}$ Moreover, it is applied to edible films and coatings ${ }^{4}$ when making carrageenan film sheets with nanocellulose. ${ }^{6}$ The use of CMC in bioplastic formulations can increase the physical properties of bioplastics; it can also serve as a binder, thickener, and emulsion stabilizer. ${ }^{7}$ Glycerol has important roles as natural plasticizer to improve the flexibility and processability of polymers. Carrageenan will make bioplastic more brittle during the melt-mixing process, so a plasticizer, such as glycerol, would lower the second order transition temperature, the glass transition temperature $(\mathrm{Tg}){ }^{8}$

To the best of the authors' knowledge, research on the use of carrageenan in starch-CMC bioplastics has not been conducted so far. Thus, the effect of adding carrageenan to starch bioplastics needs to be investigated. This study aimed to determine the effect of carrageenan on the mechanical and thermal properties, and biodegradability of starch-CMC bioplastics.

\section{EXPERIMENTAL \\ Materials}

Kappa-carrageenan was provided by the Research Center for Marine and Fisheries Product Processing and Biotechnology, Ministry of Marine Affairs and Fisheries, Republic of Indonesia (Jakarta, Indonesia). CMC was provided by PT Brataco (Bekasi, Indonesia). Cassava starch was obtained from PT Surya Pati Kencana (Pati, Indonesia) and glycerol from PT Wilmar Nabati Indonesia (Jakarta, Indonesia). Salt agar medium was provided by Merck (Darmstadt, Germany).

\section{Methods \\ Preparation of bioplastic}

The starch-CMC bioplastic formulation consisted of CMC, cassava starch, glycerol and water at a ratio of 10:20:5:15 (w/w). They were pre-mixed with varying concentrations of $\kappa$-carrageenan, using a Philips Blender HR2118/01 for $3 \mathrm{~min}$. The carrageenan used represented $0 \%, 10 \%, 15 \%, 20 \%$, $25 \%$ and $30 \%$ from the total of starch-CMC bioplastic formulation ratio. The bioplastic mixture was meltmixed in a Labo Plastomil 30R150 Toyoseiki mixer at $130{ }^{\circ} \mathrm{C}$ for $4 \mathrm{~min}$. The mixture was molded via compression molding at $150{ }^{\circ} \mathrm{C}\left(5 \mathrm{~min}, 30 \mathrm{kgf} / \mathrm{cm}^{2}\right)$ to form a bioplastic sheet.

\section{Characterization of bioplastic}

Morphology of bioplastics

The cross-sectional morphology of bioplastics was observed via scanning electron microscopy (SEM energy-dispersive X-ray spectroscopy (EDS) (Jeol JSM-IT300; Tokyo, Japan). Before the analysis, the samples were covered with a thin layer of gold (10 $\mathrm{nm})$. The analysis was conducted using an accelerating voltage of $20 \mathrm{kV}$.

Fourier transform infrared spectroscopy analysis

The interaction of functional groups (Fourier transform infrared spectroscopy, Nicolet iS ATR iD5 Thermo Scientific, Madison WI, USA) was analyzed using the attenuated total reflectance method. The wavenumber ranged from 500 to $4000 \mathrm{~cm}^{-1}$.

\section{Mechanical properties of bioplastics}

The tensile strength and elongation of bioplastics were evaluated using a universal testing machine (Shimadzu IS, Kyoto, Japan) with a load cell of $1 \mathrm{kN}$, expressed as mean $\pm \mathrm{SD}(\mathrm{n}=5)$. The measurement was performed according to ASTM D638-14. The elongation was measured from the clamp movement sensor on the universal testing machine (Shimadzu IS, Kyoto, Japan), whereas the modulus of elasticity was calculated from the maximum stress divided by the corresponding elongation.

\section{Thermal properties of bioplastics}

The thermal behavior of bioplastics was analyzed via differential scanning calorimetry (DSC) using 214 Polyma Netzsch (Germany), in the temperature range of $25-250{ }^{\circ} \mathrm{C}$ at a heating rate of $10{ }^{\circ} \mathrm{C} / \mathrm{min}$ under nitrogen atmosphere. The samples were first ovendried at $105{ }^{\circ} \mathrm{C}$ for $30 \mathrm{~min}$ before the DSC analysis. The Linseis STA Platinum Series (Germany) was used for the thermogravimetric analysis (TGA) in the temperature range of $25-500{ }^{\circ} \mathrm{C}$ at a heating rate of 10 ${ }^{\circ} \mathrm{C} / \mathrm{min}$.

\section{Contact angle of bioplastics}

The bioplastic samples were placed in a glass object, and water was added dropwise to the sample. The measurement was performed directly by taking pictures at the tangent angle at the three-phase equilibrium interface point (the sessile drop method). ${ }^{9}$ The contact angle calculation was performed using ImageJ.

\section{Biodegradability of bioplastics}

The samples $(1.5 \times 1.5 \mathrm{~cm})$ were placed in a Petri dish containing salt agar medium. Aspergillus niger (5 $\mu \mathrm{L}$ ) was dropped and spread on the surface, using a disposable sterile spreader, and then incubated at $35^{\circ} \mathrm{C}$ 
and $90 \%$ relative humidity $(\mathrm{RH})$ for 6 days (modified ASTM G21-70). ${ }^{10}$

\section{RESULTS AND DISCUSSION}

Figure 1 shows the tensile strength and elongation at break of the starch-CMC bioplastics with varying ratios of $\kappa$-carrageenan. The results of the tensile test revealed that a higher amount of $\kappa$-carrageenan increased the strength of the starch-CMC bioplastics. According to the mechanical properties test, $30 \%$ loading of $\mathrm{k}$ carrageenan showed the best result for the overall mechanical performance. With the addition of $30 \% \kappa$-carrageenan, the strength of the starchCMC bioplastics increased to $15.7 \mathrm{MPa}$, whereas that without $\kappa$-carrageenan was $1.7 \mathrm{MPa}$. The increase in the tensile strength of the starch-CMC bioplastics was due to the interactions between the various components of the polymer-based system. ${ }^{11}$ As a reinforcement agent, $\kappa$-carrageenan interacts with the starch-CMC bioplastics. However, the higher the $\kappa$-carrageenan content, the lower the elongation at break. Decreased elongation at break indicated that the starch-CMC bioplastics exhibited brittleness with the addition of higher amounts of carrageenan. Brittle materials are characterized by slight deformation. ${ }^{12} \kappa$-Carrageenan is known to exhibit brittle properties; ${ }^{5}$ thus, increasing its concentration reduces the elongation at break.

The elastic modulus is defined as the ratio of stress to strain, and is determined from the initial slope of the stress-strain curve. ${ }^{13}$ The elastic modulus of the bioplastics is presented in Table 1. It was found that a higher concentration of carrageenan led to an increased value of elastic modulus. The highest value was determined for the bioplastic with $30 \%$ concentration (539.2 $\mathrm{MPa})$. The improvement in elastic modulus was due to the properties of $\kappa$-carrageenan, which tends to form a rigid structure through the aggregate gel mechanism. ${ }^{14}$

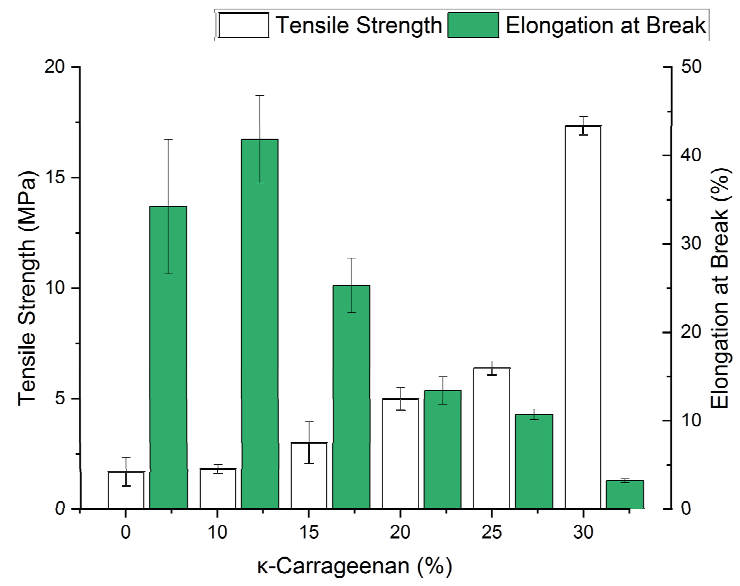

Figure 1: Tensile strength and elongation at break of starch-CMC bioplastics

Table 1

Elastic modulus of starch-CMC bioplastics

\begin{tabular}{cc}
\hline Percentage of $\kappa$-carragenan & Elastic modulus (MPa) \\
\hline $0 \%$ & 4.99 \\
$10 \%$ & 4.36 \\
$15 \%$ & 11.89 \\
$20 \%$ & 37.23 \\
$25 \%$ & 59.66 \\
$30 \%$ & 539.22 \\
\hline
\end{tabular}

The cross-sectional morphology of the bioplastics is presented in Figure 2. $\kappa$ Carrageenan can strengthen bioplastics, owing to its excellent ability to form a strong, brittle and opaque gel in bioplastic materials. ${ }^{15}$ Figure $2 \mathrm{a}$ presents the cross-sectional morphology of the starch-CMC bioplastic without $\kappa$-carrageenan. As can be seen from the figure, the surface of the 
bioplastic without $\kappa$-carrageenan is homogeneous and clean. The presence of $\kappa$-carrageenan in the bioplastics causes the cross-sectional surface to be rough. Figure 2 (b and c) shows lumps on the surface of the material. The higher the $\kappa$ carrageenan content, the clearer the $\kappa$-carrageenan granules (Fig. 2 d, e and f). The granules are in the $\kappa$-carrageenan-rich zone, which is gelatinized by water and glycerol as a co-solvent. Apart from being a plasticizer, glycerol also functions as a cosolvent that enables the $\kappa$-carrageenan gel to become more stable. Carrageenan did not dissolve in glycerol, but produced a solution that formed double helices. Therefore, the polymer from the double-helix network was more randomly formed than in water. ${ }^{16}$

Figure 2 demonstrates that $\kappa$-carrageenan bulges are firmly attached to the mixture of the starch-CMC matrix. $\kappa-$ Carrageenan can reinforce bioplastics and also binds strongly to the starch matrix. When a tensile force acted on the bioplastic, the $\kappa$-carrageenan strongly resisted on the starch-CMC matrix. Moreover, the tensile strength was increased with the increase in $\kappa$ carrageenan concentration.

Figure 3 confirms the fracture graph zone via EDS, which enabled the identification of the elements that are contained in the material. Figure 3a presents the cross-sectional morphology of bioplastic with $30 \%$ к-carrageenan. Figure $3 \mathrm{~b}$ shows the distribution of sulfur (S) generated from sulfate ester in $\kappa$-carrageenan. Carrageenan contains $\mathrm{S}$ elements that are not found in starch thermoplastics, which strengthen its mechanical properties. Based on the cross-sectional morphological images, a model material illustration is presented in Figure 4.
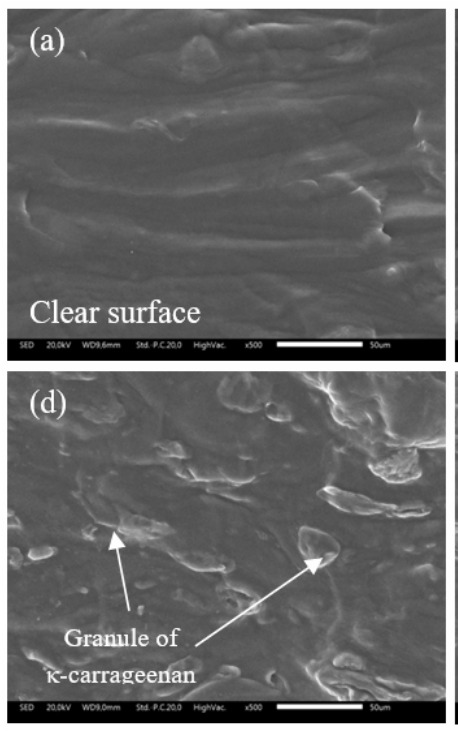
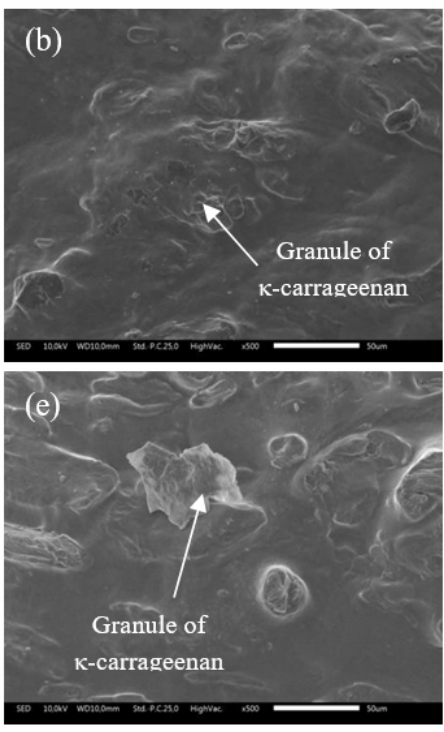
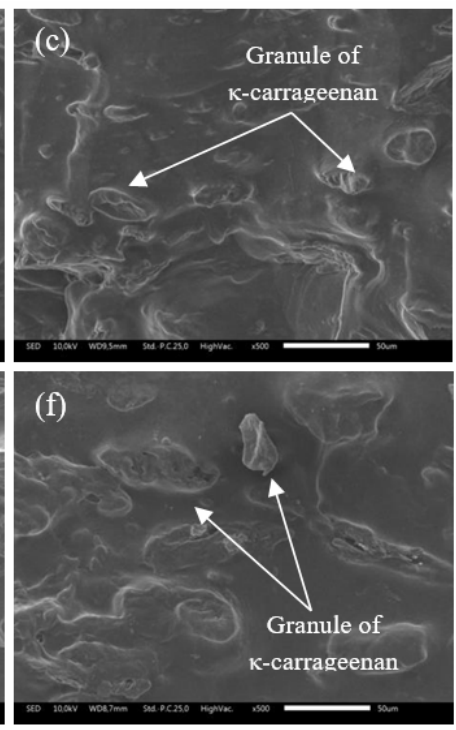

Figure 2: Cross-sectional morphology of bioplastics with $\kappa$-carrageenan in concentrations of (a) $0 \%$, (b) $10 \%$, (c) $15 \%$, (d) $20 \%$, (e) $25 \%$ and (f) $30 \%$
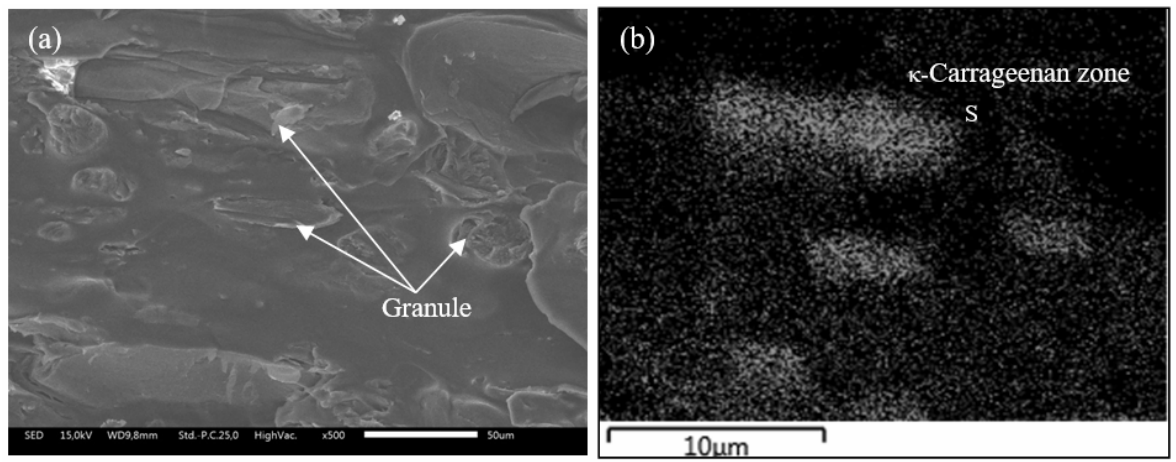

Figure 3: Bioplastic with $\kappa$-carrageenan, (a) cross-sectional morphology, (b) SEM-EDS mapping of sulfur (S) 
Bioplastics
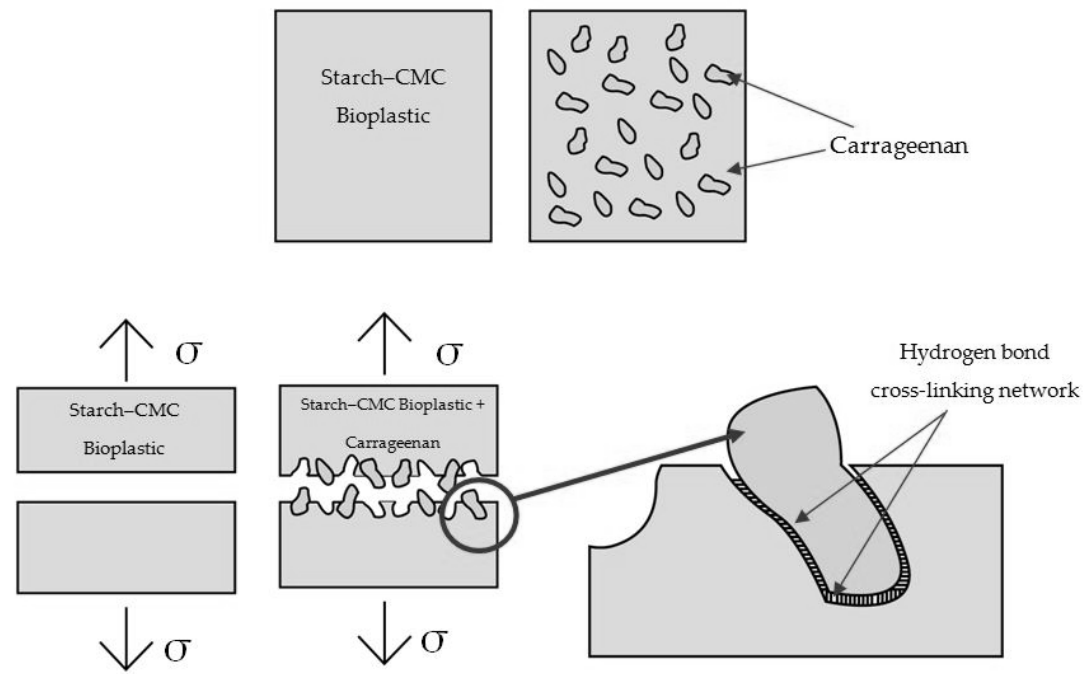

Figure 4: Material model of $\kappa$-carrageenan-based bioplastics

Bioplastics are made from a mixture of hydrocolloids, such as starch, CMC, and $\kappa-$ carrageenan. The hydrocolloid combination makes the bioplastic strong. Generally, cellulose in bioplastics has three reactive hydroxyl groups, whereas seaweed extracted compounds, such as carrageenan and alginate, have hydroxyl, carboxyl and sulfate groups. ${ }^{17}$ The combination of cellulose and seaweed derivatives forms superior gel films, due to cross-linking between components and hydrogen bonding. ${ }^{18}$ It has been proposed that strong hydrogen bonding occurs between the carrageenan and the matrix mixture of starch and CMC. ${ }^{12}$ The increase in mechanical strength of the bioplastic can be explained by the good interfacial interaction between the matrix and carrageenan as a reinforcing agent, which resulted from a tight hydrogen bond network. ${ }^{17}$ This fact was proven by FTIR.

Figure 5 presents the spectra of bioplastics with the addition of $\kappa$-carrageenan. The $\mathrm{O}-\mathrm{H}$ groups at 3500-3000 $\mathrm{cm}^{-1}$ (Fig. 5a), which widened with the increase in $\kappa$-carrageenan concentrations in the bioplastic, indicate an interaction between the starch-CMC-based bioplastic matrix and $\kappa$-carrageenan, which is a hydrogen bond cross-linking interaction. Moreover, Figure $5 \mathrm{~b}$ reveals that the band at 1330 $\mathrm{cm}^{-1}$ is due to the $\mathrm{O}-\mathrm{H}$ bending groups; the higher the $\kappa$-carrageenan concentration, the smaller the transmittance spectrum at $1330 \mathrm{~cm}^{-1}$. This is probably due to the strong hydrogen bonding in bioplastics. Based on the FTIR analysis, an adapted illustration of the hydrogen bond between
starch-CMC and carrageenan ${ }^{12,16,17}$ is presented in Figure 6.

In Figure $5 \mathrm{c}$, the absorption peak of the $\kappa$ carrageenan sulfate ester bond appears at 1224.87 $\mathrm{cm}^{-1}$. The absorption peak at $1210-1260 \mathrm{~cm}^{-1}$ indicates a $\kappa$-carrageenan sulfate ester bond. ${ }^{5}$ The half-ester sulfate groups are strongly anionic, thus causing the chemical reactivity of carrageenan. ${ }^{2}$ Because the sulfate ester groups are strongly acidic, they are always ionized, and the carrageenan molecules are still anionic (the $\mathrm{pH}$ cannot be lowered enough to remove the charge on the sulfate group). ${ }^{21}$ For bioplastics without $\kappa$ carrageenan, the peak at $1260 \mathrm{~cm}^{-1}$ indicates a C$\mathrm{O}$ bond (Fig. 5b). Conversely, for bioplastics with $\kappa$-carrageenan, no peaks appeared around 1260$1280 \mathrm{~cm}^{-1}$. A peak located in the absorption band area of $928-933 \mathrm{~cm}^{-1}$ is due to 3,6-anhydro-Dgalactose and another at $840-850 \mathrm{~cm}^{-1}$ is attributed to D-galactose-4-sulfate. ${ }^{5}$ Moreover, the absorption band from 1590 to $1640 \mathrm{~cm}^{-1}$ indicates the presence of a carbonyl group $(\mathrm{C}-\mathrm{O})$. The bands around $1427 \mathrm{~cm}^{-1}$ are due to $-\mathrm{CH}_{2}-$ scissoring and those at $1057 \mathrm{~cm}^{-1}$ are assigned to $\mathrm{CH}-\mathrm{O}-\mathrm{CH}_{2}$ stretching from the $\mathrm{CMC}$ mixture. ${ }^{19,20}$

Figure 6 shows $\kappa$-carrageenan to form hydrogen bonds with the starch-CMC matrix. This schematic reaction is supported by the FTIR results, which indicates the transmittance level of the $\mathrm{OH}$ groups (Fig. $5 \mathrm{a}$ and b), which decreases with an increase in $\kappa$-carrageenan concentration. In sum, $\kappa$-carrageenan added as a reinforcement agent in the starch-CMC matrix forms hydrogen bonding with the matrix polymers. 


\section{AKBAR HANIF DAWAM ABDULLAH et al.}
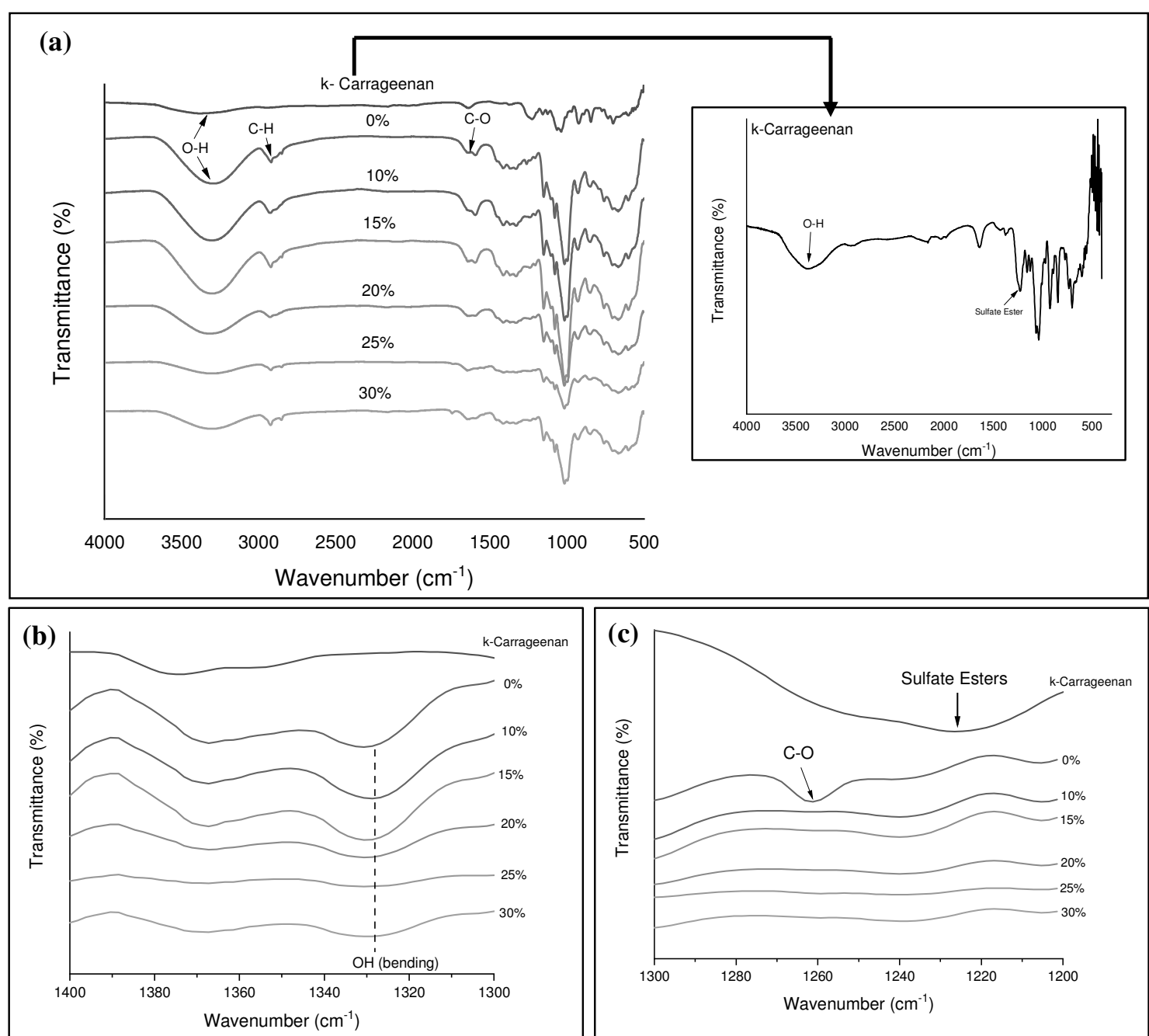

Figure 5: FTIR spectra of starch-CMC bioplastic with 0\%, 10\%, 15\%, 20\%, 25\% and 30\% א-carrageenan at (a) $4000-500 \mathrm{~cm}^{-1}$, (b) $1400-1300 \mathrm{~cm}^{-1}$, and (c) $1300-1200 \mathrm{~cm}^{-1}$

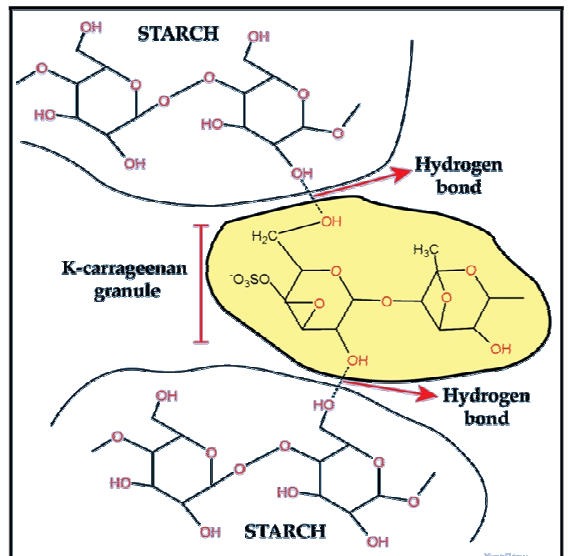

Figure 6: Schematic reaction of hydrogen bonding between the starch-CMC matrix and $\kappa$-carrageenan (adapted from literature $^{12,16,17}$ ) 


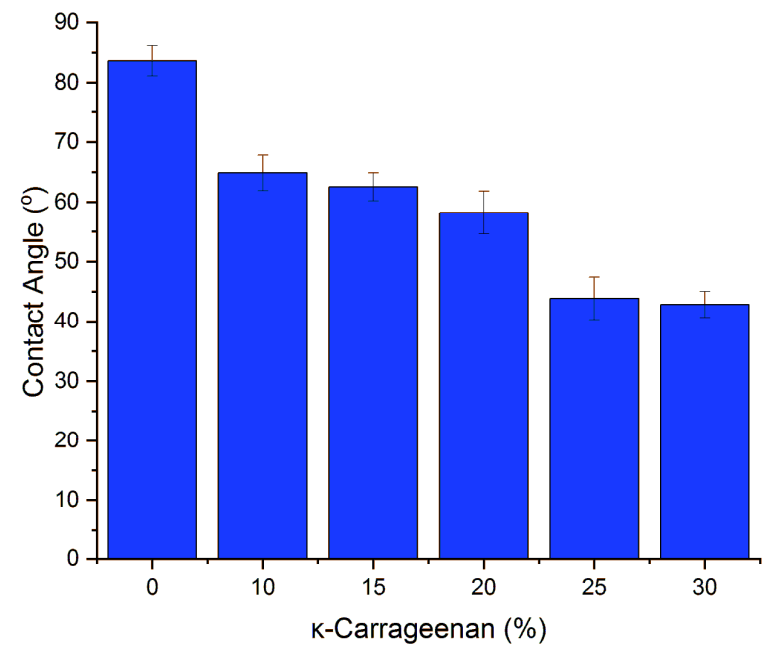

Figure 7: Contact angle of $\kappa$-carrageenan-based bioplastics

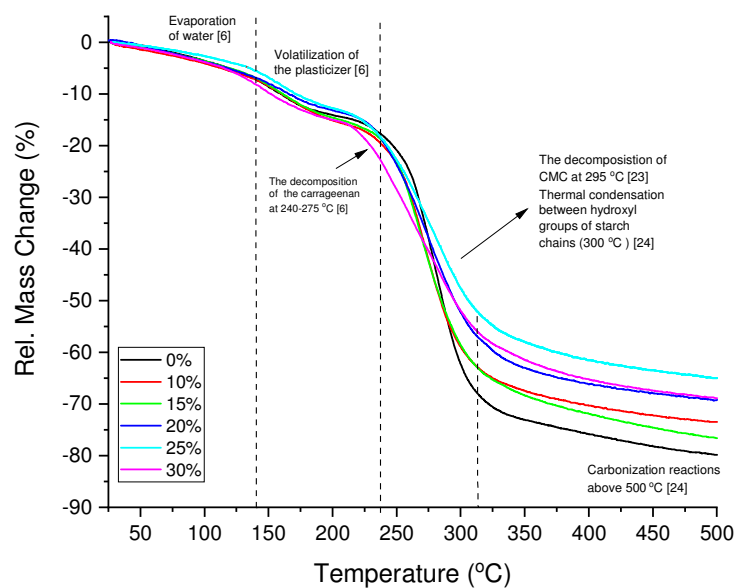

Figure 8: Thermogravimetric analysis of $\kappa$ carrageenan-based bioplastics

The addition of $\kappa$-carrageenan decreases the contact angle between the bioplastic surface and the liquid (Fig. 7); thus, it enables bioplastics to easily absorb water (hydrophilic). $\kappa$-Carrageenan contains about $25 \%-30 \%$ of sulfate ester, ${ }^{24}$ which has very high solubility. In general, sulfate and hydroxyl groups are structurally hydrophilic. ${ }^{5,21}$

Figure 8 presents the thermal degradation of bioplastics with varying concentrations of $\kappa$ carrageenan. The weight loss observed at the temperature around $50-120^{\circ} \mathrm{C}$ is attributed to the evaporation of water from the bioplastic material. ${ }^{25}$ Water molecules are bound by the hydroxyl groups on carrageenan and those on glycerol. In the temperature range of $170-225^{\circ} \mathrm{C}$, the volatile plasticizer compounds from the bioplastic decomposed. Figure 8 also shows that the mass change of the bioplastics containing $30 \%$ $\kappa$-carrageenan appears higher than that of the

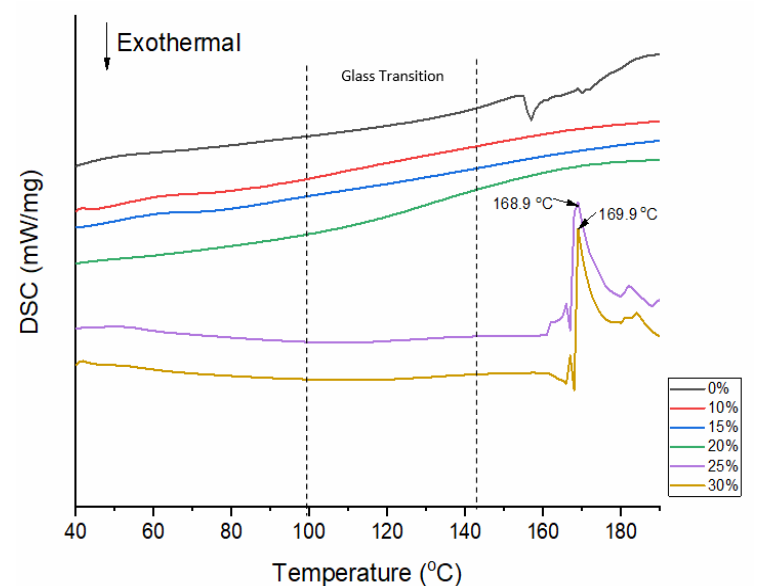

Figure 9: Differential scanning calorimetry (DSC) analysis of $\kappa$-carrageenan-based bioplastics

material with $0 \% \mathrm{~K}$-carrageenan at $250{ }^{\circ} \mathrm{C}$. This is probably due to the decomposition of the $\kappa$ carrageenan polymer chains, which occurred around $240-275{ }^{\circ} \mathrm{C} .{ }^{6}$ The primary decomposition of CMC occurred at $295{ }^{\circ} \mathrm{C},{ }^{26}$ whereas the thermal condensation between the hydroxyl groups of starch occurred at $300{ }^{\circ} \mathrm{C} .{ }^{27}$ Based on the TGA analysis, the lowest mass reduction occurred upon the addition of $25 \% \mathrm{\kappa}$-carrageenan. The mass of the bioplastic with $25 \%$ Kcarrageenan decreased by $48 \%$, whereas the mass of the material without $\kappa$-carrageenan decreased by $62.7 \%$.

Based on the results displayed in the DSC graph (Fig. 9), the glass transition of the $\kappa$ carrageenan-based bioplastics appeared in the temperature range of $100-143{ }^{\circ} \mathrm{C}$ for concentrations of $0,10,15$ and $20 \%$. Also, it should be noted that the melting point appeared at 
higher $\kappa$-carrageenan concentrations of 25 and $30 \%$, namely, at $169.9{ }^{\circ} \mathrm{C}$, which was detected by the endothermic peak. As reported earlier, $\kappa$ carrageenan demonstrated a melting point of about $80.2{ }^{\circ} \mathrm{C} .{ }^{28}$ The endothermic peak was attributed to the gel-sol transition caused by the dissociation of double helices in the mechanism of the $\kappa$-carrageenan gel formation. ${ }^{29} \kappa$ Carrageenan increases the crystallinity of bioplastics, ${ }^{27,28}$ thus, the addition of carrageenan at a particular concentration increases the melting point.

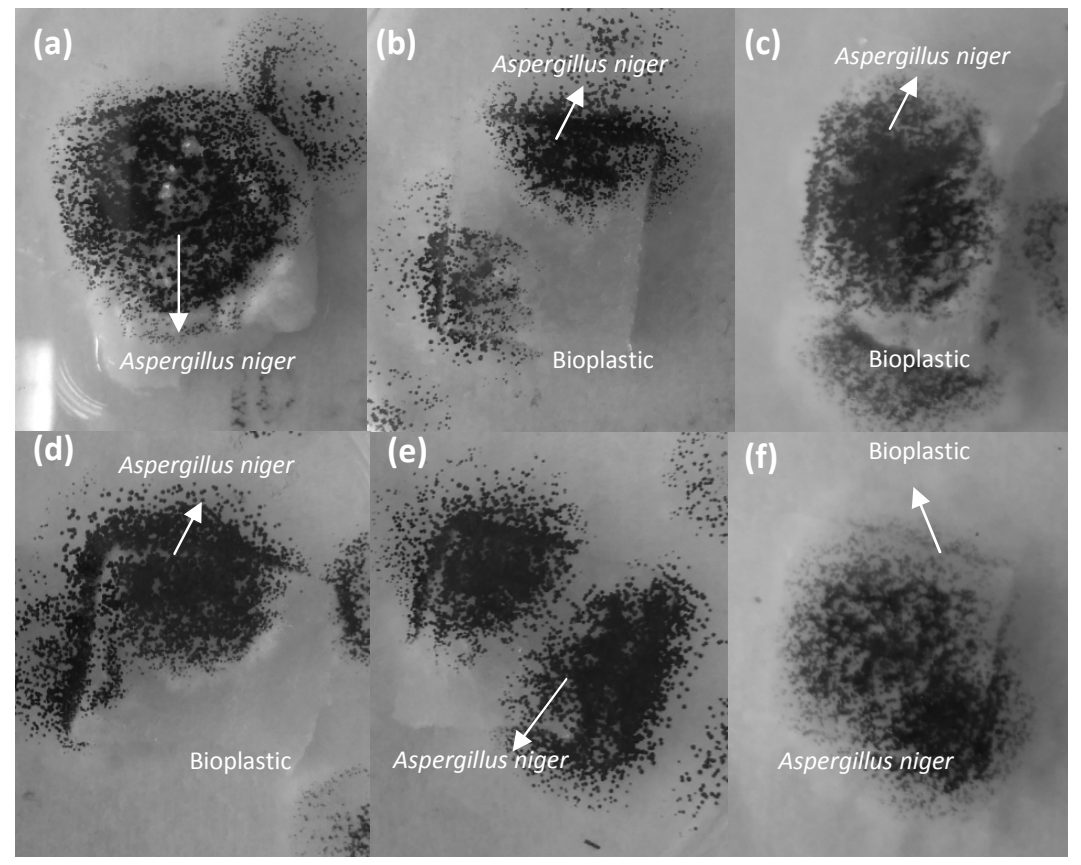

Figure 10: Biodegradability test results of bioplastics containing $\kappa$-carrageenan: (a) $0 \%$, (b) 10\%, (c) $15 \%$, (d) $20 \%$, (e) $25 \%$, and (f) $30 \%$ after six days

The biodegradability test aimed to evaluate the effect of $\kappa$-carrageenan addition on the biodegradability of the starch-carboxymethyl cellulose bioplastics. The biodegradability of the developed bioplastics was evaluated based on the growth area of Aspergillus niger in 6 days (modified ASTM G21-70 method). ${ }^{10}$ Figure 10 presents the growth area of Aspergillus niger on the bioplastic materials with various concentrations of $\kappa$-carrageenan. It reveals that the concentration of $\kappa$-carrageenan $(0 \%, 10 \%$, $15 \%, 20 \%, 25 \%$, and $30 \%$ ) did not affect the process of bioplastic degradation by Aspergillus niger. Thus, it can be concluded that $\kappa$ carrageenan does not inhibit the process of microbial decomposition of the developed bioplastic, which is of great importance for its practical application as it can be recommended as an environmentally friendly material.

\section{CONCLUSION}

$\kappa$-Carrageenan can strengthen starchcarboxymethyl cellulose (CMC) bioplastics, as evidenced by the results of the tensile strength test, which revealed that the tensile strength increased with a rising $\kappa$-carrageenan concentration. The cross-sectional morphology and energy-dispersive spectroscopy analyses indicated the presence of $\kappa$-carrageenan granules. $\kappa$-Carrageenan acts as a reinforcement agent in the starch-CMC bioplastic, forming hydrogen bonds with the matrix components, as has been proved by FTIR analysis. The addition of $\kappa$ carrageenan to the starch-CMC bioplastic can mitigate mass loss, and enhancing the thermal stability of the material. The lowest mass reduction $(48 \%)$ occurred in the bioplastic comprising $25 \%$ of $\kappa$-carrageenan. The addition of $\kappa$-carrageenan did not affect the biodegradability of the developed bioplastic, 
which thus recommends it as an environmentally friendly material.

ACKNOWLEDGMENTS: The authors gratefully acknowledge support from Research Unit for Clean Technology, Indonesian Institute of Sciences and Research Center for Marine and Fisheries Product, Processing and Biotechnology, Ministry of Marine Affairs and Fisheries, Republic of Indonesia. The authors would like to thank Enago (www.enago.com) for the English language review.

\section{REFERENCES}

1 L. Ribba, N. L. Garcia, N. D'Accorso and S. Goyanes, in "Starch-Based Materials in Food Packaging: Processing, Characterization and Applications", Elsevier Inc., 2017, p. 37-76, http://dx.doi.org/10.1016/B978-0-12-809439-6.000030

2 J. Necas and L. Bartosikova, Vet. Med. (Praha), 58, 187 (2013), http://doi.org/10.17221/6758-VETMED

3 H. Suryanto, L. P. Mahera, F. A. Kharismawan, S. M. Saragih, S. Solichin et al., J. Eng. Sci. Technol. Rev., $\quad \mathbf{1 2}, \quad 122$ http://doi.org/10.25103/jestr.125.14

4 A. R. V. Ferreira, V. D. Alves and I. M. Coelhoso, Membranes (Basel), $\quad$ 6, 1 (2016), http://doi.org/10.3390/membranes6020022

5 CP Kelco, "Carrageenan Book", CP Kelco ApS, Lille Skensved, Denmark, 2001

6 B. B. Sedayu, M. J. Cran and S. W. Bigger, Polymers (Basel), 12, $1145 \quad$ (2020), http://doi.org/10.3390/POLYM12051145

7 D. Ariyani, E. Puryati Ningsih and S. Sunardi, Indones. J. Chem. Res., 7, 77 (2019), http://doi.org/10.30598//ijcr.2020.7-sun

8 M. G. A. Vieira, M. A. Da Silva, L. O. Dos Santos and M. M. Beppu, Eur. Polym. J., 47, 254 (2011), http://doi.org/10.1016/j.eurpolymj.2010.12.011

9 R. S. Hebbar, A. M. Isloor and A. F. Ismail, in "Membrane Characterization", edited by N. Hilal, A. Fauzi Ismail, T. Matsuura, D. Oatley-Radcliffe, Elsevier, 2017, Contact Angle Measurements, pp. 219255, https://doi.org/10.1016/B978-0-444-637765.00012-7

10 R. C. Nissa, A. K. Fikriyyah, A. H. D. Abdullah and S. Pudjiraharti, in IOP Conference Series: Earth and Environmental Sciences, 277, 012007 (2019), http://doi.org/10.1088/1755-1315/277/1/012007

11 J. M. R. C. A. Santos and J. T. Guthrie, Mater. Sci. Eng. Rep., 50, $79 \quad$ (2005), http://doi.org/10.1016/j.mser.2005.07.003

12 W. Brostow and H. E. Hagg Lobland, J. Mater.
Sci., 45, 242 (2010), http://doi.org/10.1007/s10853009-3926-5

13 D. E. Albert, "Methods for Verifying Medical Device Cleanliness", vol. 7, Elsevier Inc., 2015

14 H. Suryanto, A. W. Rahmawan, Solichin, R. T. Sahana, M. Muhajir et al., IOP Conference Series: Materials Science and Engineering, 494, 012075 (2019), $899 X / 494 / 1 / 012075$

15 J. H. Lin, C. W. Liang and Y. H. Chang, Food Hydrocoll., $\quad$ 60, $\quad 509 \quad$ (2016), http://doi.org/10.1016/j.foodhyd.2016.04.024

16 S. Ramakrishnan and R. K. Prud'Homme, Carbohyd. Polym., 43, $327 \quad$ (2000), http://doi.org/10.1016/S0144-8617(00)00177-6

17 H. P. S. Abdul Khalil, Y. Tye, C. K. Saurabh, C. P. Leh, T. K. Lai et al., Express Polym. Lett., 11, 244 (2017), http://doi.org/10.3144/expresspolymlett.2017.26

18 S. Rudhziah, M. S. A. Rani, A. Ahmad, N. S. Mohamed and H. Kaddami, Ind. Crop. Prod., 72, 133 (2015), http://doi.org/10.1016/j.indcrop.2014.12.051

19 P. S. Chauhan and A. Saxena, 3 Biotech, 6, 1 (2016), http://doi.org/10.1007/s13205-016-0461-3

20 M. Afif, N. Wijayati and S. Mursiti, Indones. J. Chem. Sci., 7, 102 (2018)

21 J. N. BeMiller, in "Carbohydrate Chemistry for Food Scientists", edited by J. N. BeMiller, AACC International Press, 2019, pp. 279-291, http://doi.org/10.1016/B978-0-12-812069-9.00013-3

22 R. Ergun, J. Guo and B. Huebner-Keese, in "Encyclopedia of Food and Health", edited by B. Caballero, P. M. Finglas, F. Toldrá, Academic Press, 2015, pp. 694-702, http://doi.org/10.1016/B978-0-12384947-2.00127-6

23 D. de Britto, J. S. de Rizzo and O. B. G. Assis, Int. J. Polym. Anal. Charact., 17, 302 (2012), http://doi.org/10.1080/1023666X.2012.668449

24 L. Cunha and A. Grenha, Mar. Drugs, 14, 42 (2016), http://doi.org/10.3390/md14030042

25 S. Zarina and I. Ahmad, BioResources, 10, 256 (2015), http://doi.org/10.15376/biores.10.1.256-271

26 M. El-Sakhawy, H. A. S. Tohamy, A. Salama and S. Kamel, Cellulose Chem. Technol., 53, 667 (2019), http://doi.org/10.35812/CelluloseChemTechnol.2019.5 3.65

${ }^{27}$ X. Liu, Y. Wang, L. Yu, Z. Tong, L. Chen et al., Starch/Staerke, $\quad \mathbf{6 5}, \quad 48 \quad$ (2013), http://doi.org/10.1002/star.201200198

28 D. Setijawati, S. Wijana and I. Santosa, Teknol. Pangan Media Inf. dan Komun. Ilm. Teknol. Pertan., 2 (2011), http://doi.org/10.35891/tp.v2i1.481

29 M. Iijima, M. Takahashi, T. Hatakeyama and H. Hatakeyama, J. Therm. Anal. Calorim., 114, 895 (2013), http://doi.org/10.1007/s10973-013-2953-2 